\title{
Dynamic Optimization of Constrained Layer Damping Structure for the Headstock of Machine Tools with Modal Strain Energy Method
}

\author{
Yakai Xu, ${ }^{1}$ Weiguo Gao, ${ }^{1}$ Yuhan Yu, ${ }^{2}$ Dawei Zhang, ${ }^{1}$ Xiangsong Zhao, ${ }^{1}$ \\ Yanling Tian, ${ }^{1,3}$ and Huaying $\mathrm{Cun}^{4}$ \\ ${ }^{1}$ Key Laboratory of Mechanism Theory and Equipment Design, Ministry of Education, Tianjin University, Tianjin 300072, China \\ ${ }^{2}$ School of Electrical Engineering and Automation, East China Jiaotong University, Nanchang 330013, China \\ ${ }^{3}$ School of Engineering, University of Warwick, Coventry CV4 7AL, UK \\ ${ }^{4}$ Shenji Group Kunming Machine Tool Company Limited, Kunming 650203, China
}

Correspondence should be addressed to Weiguo Gao; gaowg@tju.edu.cn

Received 3 November 2016; Accepted 31 January 2017; Published 22 February 2017

Academic Editor: Sergio De Rosa

Copyright ( 2017 Yakai Xu et al. This is an open access article distributed under the Creative Commons Attribution License, which permits unrestricted use, distribution, and reproduction in any medium, provided the original work is properly cited.

\begin{abstract}
Dynamic stiffness and damping of the headstock, which is a critical component of precision horizontal machining center, are two main factors that influence machining accuracy and surface finish quality. Constrained Layer Damping (CLD) structure is proved to be effective in raising damping capacity for the thin plate and shell structures. In this paper, one kind of high damping material is utilized on the headstock to improve damping capacity. The dynamic characteristic of the hybrid headstock is investigated analytically and experimentally. The results demonstrate that the resonant response amplitudes of the headstock with damping material can decrease significantly compared to original cast structure. To obtain the optimal configuration of damping material, a topology optimization method based on the Evolutionary Structural Optimization (ESO) is implemented. Modal Strain Energy (MSE) method is employed to analyze the damping and to derive the sensitivity of the modal loss factor. The optimization results indicate that the added weight of damping material decreases by $50 \%$; meanwhile the first two orders of modal loss factor decrease by less than $23.5 \%$ compared to the original structure.
\end{abstract}

\section{Introduction}

As one of important kinds of CNC machine tools, high speed precision horizontal machining center is the key equipment in automotive, aerospace, and precision mold industry areas. Traditional machine tool structures are made of highstiffness metals, such as steel and cast iron. However, for their low damping capacity, additional damping treatments are usually to be applied. Kim and Chang [1] developed carbon/epoxy composite-aluminum hybrid structures with friction layers on the column and spindle holders to increase structural damping of machine tool. The compositealuminum hybrid spindle holder employing a friction layer has more than $530 \%$ increment of damping capacity than the original spindle holder. Rashid and Nicolescu [2] applied
Tuned Viscoelastic Dampers (TVDs) to work-holding systems by contacting work-piece for vibration control of milling machines. This damping mechanism was both easy to implement and able to cover a wide range of frequencies. Chang et al. [3] applied glass fiber epoxy composite material at the surface of the headstock of a precision grinding machine to reinforce damping capacity. It is found that the hybrid headstock resulted in $12 \%$ stiffness increase and $212 \%$ increase of the loss factor compared with the steel headstock. Lee et al. [4] applied a hybrid column by adhesively bonding glass fiber reinforced epoxy composite plates to a cast iron column to improve the damping capacity of the column of a precision grinding machine tool. From experiments, it is found that the damping capacity of the hybrid column is $35 \%$ higher than that of the cast iron column. During the machining 


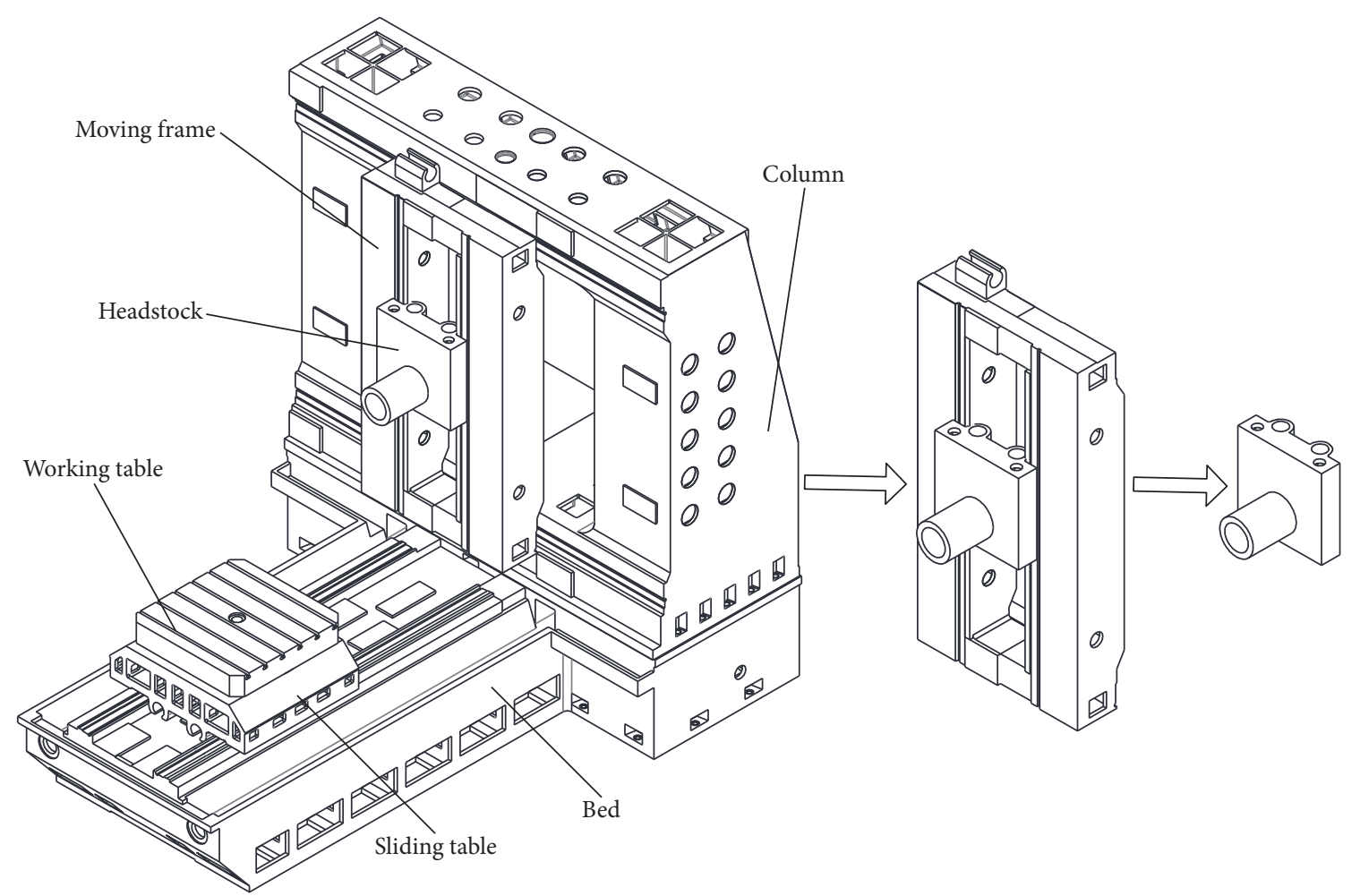

FIGURE 1: Configuration of a high speed precision horizontal machining center.

process, more than $50 \%$ of the cutting point deflection of machine tool structures comes from the headstock, with the remainder coming from beds, slides, and joint interfaces [3, 5]. Therefore, to improve the cutting performance of machine tool, the headstock of high dynamic stiffness is essential. Since the dynamic stiffness is proportional to the damping, a high damping property is an effective way to improve the dynamic stiffness.

For the structures like plates, shells, and boxes, Constrained Layer Damping (CLD) structure is an effective way to improve damping property. This structure was firstly studied by Kerwin [6], who developed a simplified theory relating the shear strain of the damping layer to the transverse motion of the structure. Thereafter numerous theoretical analyses of simple sandwich beam and plate structure were published based on the laminate theories by Ross et al. [7] and Mead and Markus [8]. Johnson and Kienholz [9] proposed an efficient method to describe complicated damping structure that modal damping ratios were estimated from undamped normal mode result by means of Modal Strain Energy (MSE) method. Good agreement of natural frequency and modal loss factor was obtained by comparing MSE method with classic complex stiffness eigenvalue method.

Full coverage passive CLD treatments are not applicable in many cases. Lall $[10,11]$ attempted to analyze a partially covered sandwich beam and plate and developed two formulations based on simplified methods, while the other one based on an exact method. Marcelin et al. [12] investigated the optimal damping of beams partially covered by constrained viscoelastic layers using a genetic algorithm, wherein the design variables were the dimensions and locations of the viscoelastic layers and the objective function was the maximum damping factor. Alvelid [13] optimized the position and shape of attached passive CLD using a modified gradient method, the objective of which was the minimum value of frequency averaged transverse vibration levels of a plate with a harmonic excitation. Lepoittevin and Kress [14] presented a new approach for finding optimum damping treatment by sectioning the constraining and constrained layers, and the loss factor for a given mode improved between $48 \%$ and $92 \%$ compared to a full coverage configuration. Guo et al. [15] studied the problem of topological optimization design for simple CLD plate on the basis of Evolutionary Structural Optimization (ESO) method. This method has certain significance on the optimization design of damping structure and has extensive application prospect in engineering. Fang and Zheng [16] proposed a topology optimization by ESO method to minimize the resonant response of plates with CLD treatment under specified broadband harmonic excitations. Kim et al. [17] designed an optimal damping layout of an unconstrained-layer shell structure by employing the modal shape, the strain energy distribution, and the topology optimization methods, and it was found that topology optimization provides a higher modal loss factor. These topology methods are proved practical for the simple plates or shells, but there are few application examples for the complicated structure.

In this paper, a headstock of high speed precision horizontal machining center is investigated as shown in Figure 1. To improve the damping capacity of the headstock, CLD 


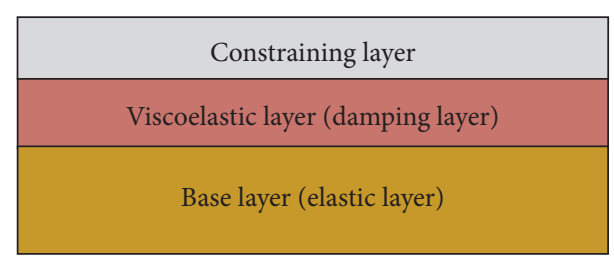

FIGURE 2: CLD structure.

structure is adhered to the surface of headstock. MSE method is employed for the modeling of the damping structure. In order to achieve the best performance, ESO topology method is implemented and an improved sensitivity is proposed for the optimization of the CLD structure.

\section{Methods of Modeling and Topology Optimization of CLD Structure}

2.1. Modeling of CLD Structure. Complex eigenvalue, direct frequency response and MSE method are generally used in dynamic analysis of composite damping structure. The calculation of the first two methods is in complex domain. Thus, the cost will be extremely high when calculating complex structure. The MSE method is from the point of view of the energy, and the loss factor of structure is defined as the ratio of dissipation energy and total deformation energy. The damping capacity increases with the increase of the loss factor. The parameters of damping structure can be expediently analyzed and optimized using this method in the finite element analysis. Hence, the MSE method will be employed in this paper. The CLD structure is shown in Figure 2.

The strain energy of base layer $U_{p}$, viscoelastic layer $U_{v}$, constraining layer $U_{c}$, and composite structure $U$ are, respectively, expressed as

$$
\begin{aligned}
U_{p} & =\frac{1}{2}\{\Phi\}^{T}[K]_{p}\{\Phi\} \\
U_{v} & =\frac{1}{2}\{\Phi\}^{T}[K]_{v}\{\Phi\} \\
U_{c} & =\frac{1}{2}\{\Phi\}^{T}[K]_{c}\{\Phi\} \\
U & =\frac{1}{2}\{\Phi\}^{T}[K]\{\Phi\},
\end{aligned}
$$

where $\{\Phi\}$ is real vector of the associated undamped system and $[K]_{p},[K]_{v},[K]_{c}$, and $[K]$ are the stiffness matrix of base layer, viscoelastic layer, constraining layer, and the composite structure, respectively; their relationship can be expressed by

$$
[K]=[K]_{p}+[K]_{v}+[K]_{c} .
$$

The energy dissipation of damping material in a cycle $W$ can be expressed as

$$
W=\frac{1}{2} \beta\{\Phi\}^{T}[K]_{v}\{\Phi\}
$$

Then, the loss factor of composite structure $\eta$ is obtained as

$$
\eta=\frac{W}{U}=\frac{\beta U_{v}}{U_{p}+U_{v}+U_{c}} .
$$

2.2. Topology Optimization of CLD Structure. In order to achieve the best performance of a CLD structure considering various constraints such as lightweight and low-cost, the shape and layout of damping material should be optimized in the design domains. Topology optimization is a good solution for this problem. The ESO method, one of design methods of topology optimization based on the simple concept of gradually removing inefficient material from structure, is extensively employed. As a numerical method based on finite element analysis where the design domain is discretized into the fine mesh of elements, the optimization procedure is to find every point whether there should be material (solid element) or not (void element). The ESO method is suitable for a wide range of structure design problems and easily implemented in finite element analysis software. With the removal rate of damping material being the constraint and the maximum weighted value of the damping factor being the objective, the model for damping optimization of CLD structure can be shown as follows:

$$
\begin{aligned}
& \text { Find } e=\left[e_{1}, e_{2}, e_{3}, \ldots, e_{n}\right]^{T} \\
& \operatorname{Max} \quad \eta=\sum_{r=1}^{k} w_{r} \eta_{r} \quad \sum_{r=1}^{k} w_{r}=1 \\
& \text { s.t. } \quad V=\sum_{i=1}^{N} e_{i} v_{i} \leq V_{t} \quad e_{i}=\{0,1\} \\
& \omega_{r} \geq \omega_{r}^{*},
\end{aligned}
$$

where $e$ is the optimization variable, $e_{i}$ stands for the state of $i$ th element of damping layer, $e_{i}=0$ stands for the element being dead, $e_{i}=1$ stands for the element being alive, $v_{i}$ is the volume of the $i$ th element, $V_{t}$ is the maximum design allowable value of the volume for the damping material, $\eta_{r}$ stands for the $r$ th modal loss factor, $w_{r}$ is the corresponding weight coefficient, $\omega_{r}$ is the $r$ th natural frequency, and $\omega_{r}^{*}$ stands for the minimum design allowable value of the $r$ th natural frequency.

In the finite element analysis, dynamics eigenvalue equation of the undamped structure is expressed as

$$
\left([K]-\omega_{r}[M]\right)\left\{\Phi_{r}\right\}=0,
$$

where $[K]$ is the stiffness matrix of the structure, $[M]$ is the mass matrix of the structure, and $\Phi_{r}$ is the eigenvector of the $r$ th natural frequency

According to the MSE method, the $r$ th modal loss factor of composite structure can be obtained from the energy distribution in the structure by

$$
\eta_{r}=\frac{\beta U_{r v}}{U_{r}}=\frac{\beta U_{r v}}{U_{r b}+U_{r v}+U_{r c}},
$$


where $U_{r b}, U_{r v}, U_{r c}$, and $U_{r}$ are the strain energy of base layer, viscoelastic layer, constraining layer, and the whole structure in the considered mode $r$, respectively.

In the finite element analysis, when the $i$ th element of damping layer is removed, the corresponding element of constraining layer at the same location is also removed. The variation of the $r$ th modal loss factor of composite structure is [15]

$$
\Delta \eta_{r}=\beta\left(\frac{\Delta U_{r v}}{U_{r}}-\frac{\Delta U_{r} U_{r v}}{U_{r}^{2}}\right) .
$$

In the process of iteration, because the number of removed elements every time is constrained, the change of structure is extremely small. Assume that the real vector $\{\Phi\}$ is nearly the same after the $i$ th element is removed, during the process of optimization, the modal shape is considered as consistent in the two-iteration step. Thus, the variation of strain energy of damping layer can be considered as

$$
\begin{aligned}
\Delta U_{r v} & \approx \frac{1}{2}\left\{\Phi_{r}\right\}^{T}[\Delta K]\left\{\Phi_{r}\right\}=-\frac{1}{2}\left\{\varphi_{r}^{i}\right\}^{T}\left[K_{i}\right]\left\{\varphi_{r}^{i}\right\} \\
& =-U_{r v i},
\end{aligned}
$$

where $\left[K_{i}\right]$ is the stiffness matrix of the $i$ th element of the viscoelastic layer, $\left\{\varphi_{r}{ }^{i}\right\}$ is the eigenvector of the $i$ th element in the $r$ th natural frequency, and $U_{r v i}$ is the strain energy of the $i$ th element of viscoelastic layer in the considered mode $r$.

Similarly, the variation of strain energy of the whole structure is

$$
\Delta U_{r} \approx-\left(U_{r v i}+U_{r c i}\right)
$$

where $U_{r c i}$ is the strain energy of the $i$ th element of constraining layer in the considered mode $r$.

Substituting (12) and (13) into (11) yields

$$
\Delta \eta_{r}=\frac{\beta}{U_{r}}\left(\frac{\left(U_{r v i}+U_{r c i}\right) U_{r v}}{U_{r}}-U_{r v i}\right),
$$

where $\Delta \eta_{r}$ is the variation of the $r$ th modal loss factor on the $i$ th element of damping layer.

The size of the element cannot be consistent in the mesh process of the composite structure. Thus, the sensitivity of optimization is defined as the variation of the $r$ th modal loss factor on the per unit volume of the $i$ th element of damping layer, which can be expressed as

$$
\alpha_{r i}=\frac{\Delta \eta_{r i}}{v_{i}}
$$

Substituting (15) into (14) yields

$$
\alpha_{r i}=\frac{\beta}{v_{i} U_{r}}\left(\frac{\left(U_{r v i}+U_{r c i}\right) U_{r v}}{U_{r}}-U_{r v i}\right)
$$

The strain energy of the element can easily be obtained in the finite element analysis. Using ANSYS parametric design
TABLE 1: Mechanical property of each material.

\begin{tabular}{lccc}
\hline & Density $\left(\mathrm{kg} / \mathrm{m}^{3}\right)$ & Modulus $(\mathrm{GPa})$ & Poisson's ratio \\
\hline $\begin{array}{l}\text { Viscoelastic } \\
\text { material }\end{array}$ & 1100 & 0.009 & 0.49 \\
Aluminum & 2700 & 70 & 0.3 \\
\hline
\end{tabular}

TABLE 2: Comparison of FEM simulation and experiment.

\begin{tabular}{lcc}
\hline & Natural frequency $(\mathrm{Hz})$ & Modal loss factor \\
\hline FEM simulation & 255.56 & 0.167 \\
Experiment & 251.25 & 0.162 \\
\hline
\end{tabular}

language, a program is compiled to finish topology optimization. The flow chart of topology optimization process by ANSYS is shown as in Figure 3.

2.3. Experiment Verification of MSE Method. In order to verify the effectiveness of the MSE method, a plate composite specimen is manufactured and tested to measure the loss factor, as shown in Figure 4. The length and width of all layers are $400 \mathrm{~mm}$ and $300 \mathrm{~mm}$, respectively, and the thicknesses of base layer, damping layer, and constraining layer are $4 \mathrm{~mm}, 2 \mathrm{~mm}$, and $2 \mathrm{~mm}$, respectively. The base layer and constraining layer are made of aluminum, and the mechanical properties of each material are listed in Table 1. The exciting force is applied at point 1 , and the output signal is picked up at point 2 .

The loss factor and natural frequency were tested by the impulse-frequency response test. The testing apparatus consisted of an input module (B\&K 3050), an impulse hammer (B\&K 8206), and an accelerometer (B\&K 4506). A force transducer is integrated on the hammer. Natural frequency and loss factor were measured by giving impulses on the specimen suspended with thin strings as shown in Figure 5. The loss factor was calculated by the half power band width method as follows:

$$
\eta=\frac{f_{2}-f_{1}}{f_{r}}
$$

where $f_{r}$ is the resonant frequency, $f_{1}$ is the left side frequency of the half power band, and $f_{2}$ is the right side frequency of the half power band.

Figure 6 shows the measured loss factor of the specimen. In the FEM simulation, through the modal analysis, the frequency and strain energy of each material at each mode can be obtained. Thus, the modal loss factor can be calculated by the MSE method according to (10). The loss factor of viscoelastic material changes with the temperature and frequency, and the temperature is the most important influencing factor. In the experiment, the environment temperature is invariable; thus, the loss factor is set to be constant value 0.6 in the FEM simulation. The comparison between the MSE method and experiment is listed in Table 2. It can be seen that the results of simulation and experiment match well with each other, which demonstrates that the MSE method is reliable. 


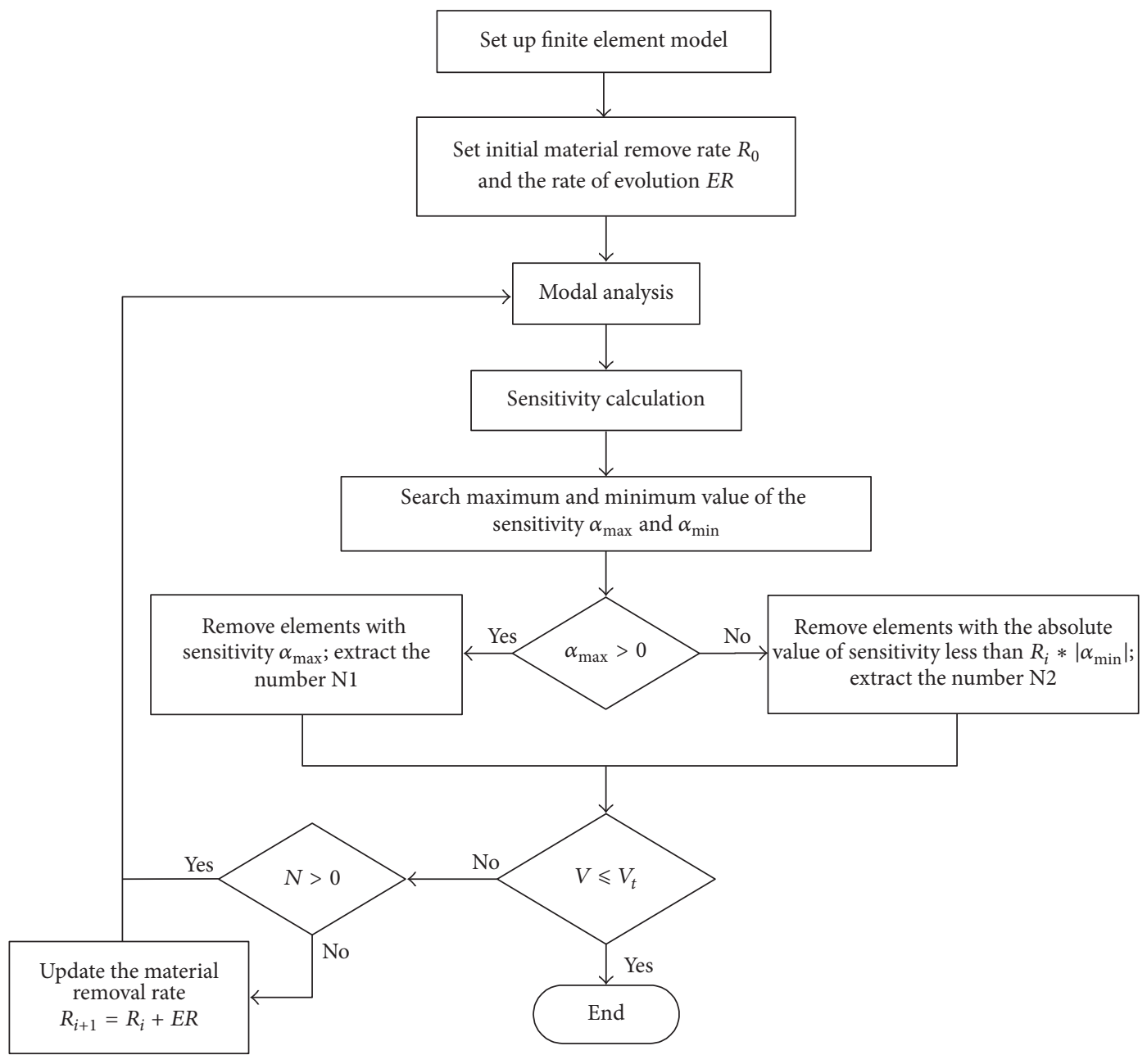

FIGURE 3: Flow chart of topology optimization process by ANSYS.

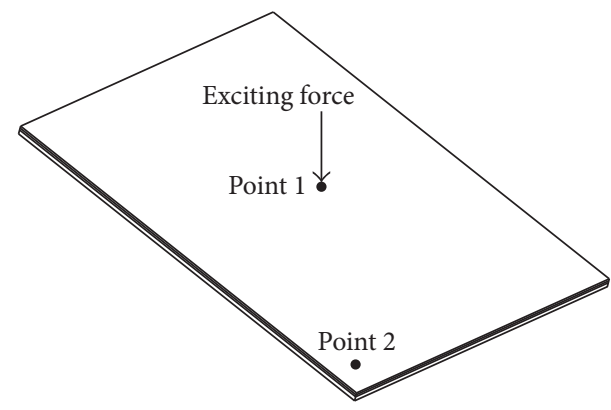

(a) The sketch

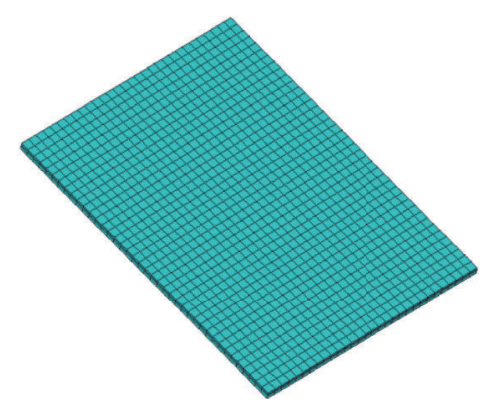

(b) The finite element model

Figure 4: Flat panel sample.

\section{Simulation of Headstock with Damping Material}

3.1. Dynamic Analysis of the Original Headstock with Constraint. To estimate the dynamic characteristics of the original headstock, finite element analysis is performed by treating spindle and headstock as a unified whole. The headstock is made of cray iron. Young's modulus, density, and Poisson's ratio are $178 \mathrm{GPa}, 7450 \mathrm{~kg} / \mathrm{m}^{3}$, and 0.3 , respectively. To simulate the actual constraint state, the headstock is constrained with $Y$ direction freedom at the position connected with screw nuts, with $X$ and $Z$ direction freedoms at the position connected with slide blocks, as shown in Figure 7. The solid186 element is employed to model the structure. 

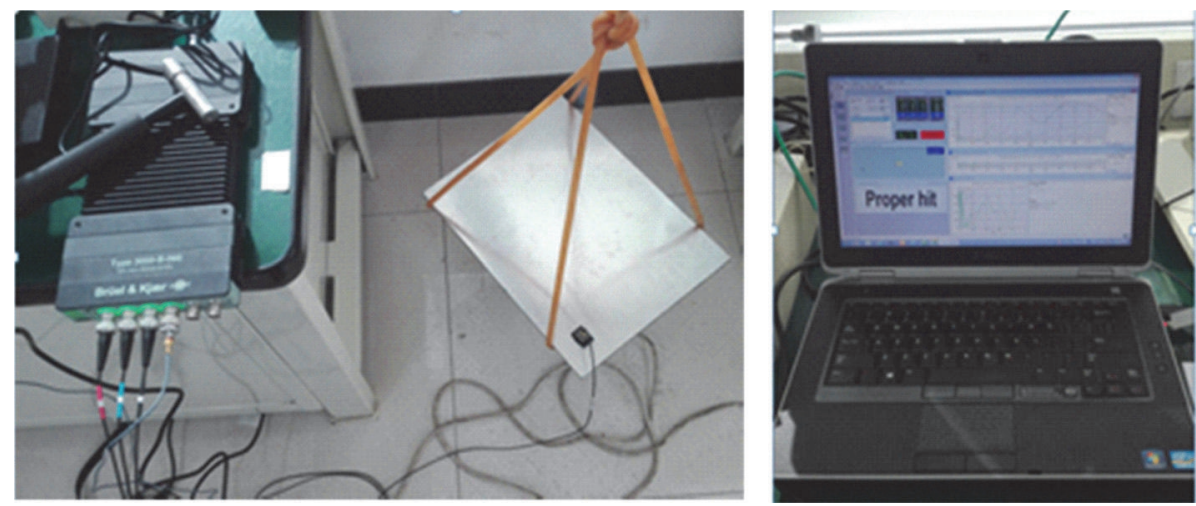

Figure 5: The specimen and test system.

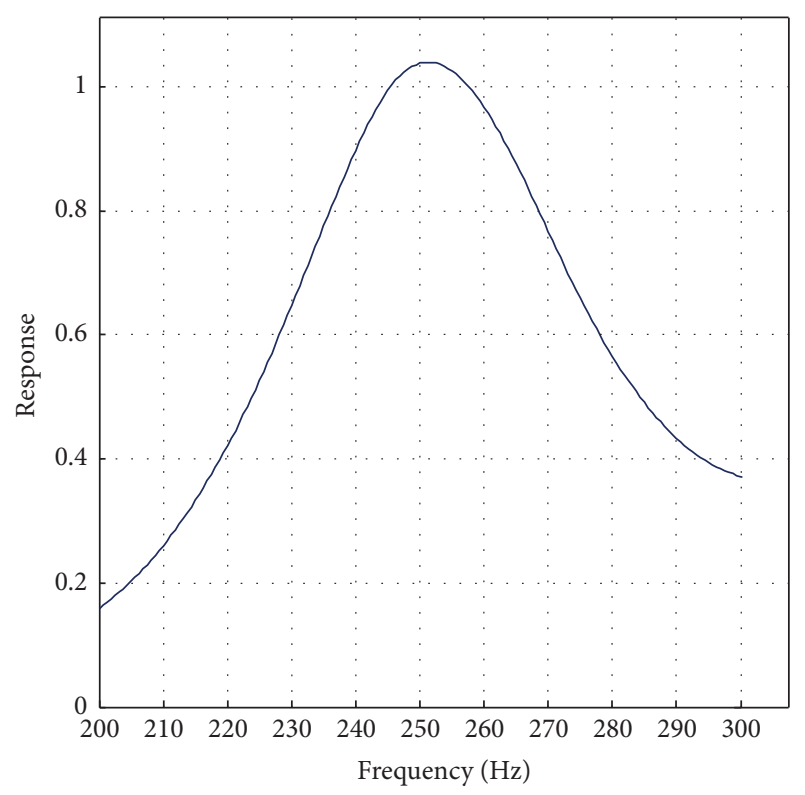

FIGURE 6: The frequency-domain response.

The modal analysis is performed, with the first threeorder frequencies being $386.91 \mathrm{~Hz}, 387.99 \mathrm{~Hz}$, and $666.60 \mathrm{~Hz}$, respectively. Since the headstock is approximate symmetry, the values of the first and second frequencies are close. The modal shapes are shown in Figure 8. At the first- and second-order natural frequencies, the cylinder part swings in the vertical and horizontal direction, respectively. At the third order, the front face contacted with the cylinder part twist forward and backward. To obtain the frequency response, harmonic response analysis with mode superposition method is performed. A harmonic exciting force of 0 to $1000 \mathrm{~Hz}$ is applied at the position connected with tool nose. The simulation results show that the response amplitude of first and second-order frequency is evidently greater than others. Thus, the optimization objective of added damping structure focus on the first and second modal loss factor.

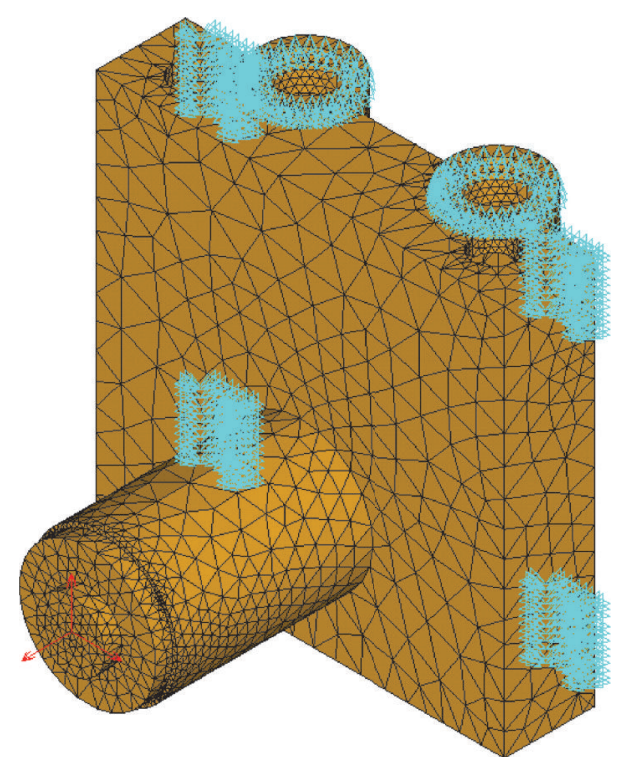

Figure 7: Finite element model of headstock with constraint.

3.2. Dynamic Analysis of the Hybrid Headstock with Constraint. To improve the damping capacity, a plate which contains a damping layer and a constraining layer is adhesively bonded to the surface of the headstock, as shown in Figure 9. The constraining layer is made of aluminum, and the damping layer is made of the same viscoelastic material as the previous experiment. The thickness of both damping layer and constraining layer influences the loss factor of the structure. If the thickness is too small, the damping effect is not obvious. If the thickness is too large, the frequency of structure will reduce obviously. The responses for several values of thickness were analyzed as shown in Figure 10. It can be seen that when the thickness of damping layer and constraining layer is $5 \mathrm{~mm}$, the damping effect is better. Thus, the thickness of damping layer and constraining layer is adopted with $5 \mathrm{~mm}$, respectively, in this paper. 


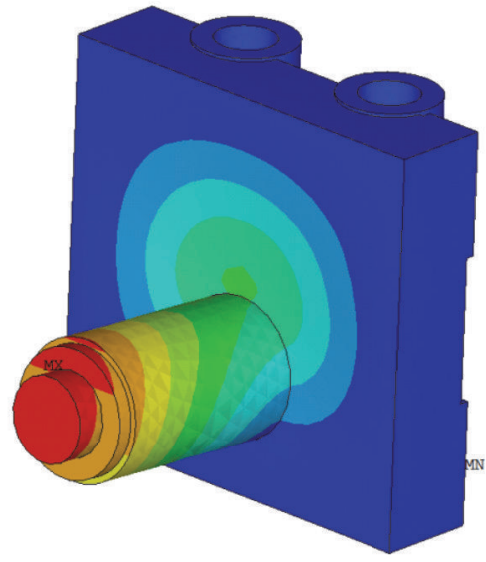

(a) The first order

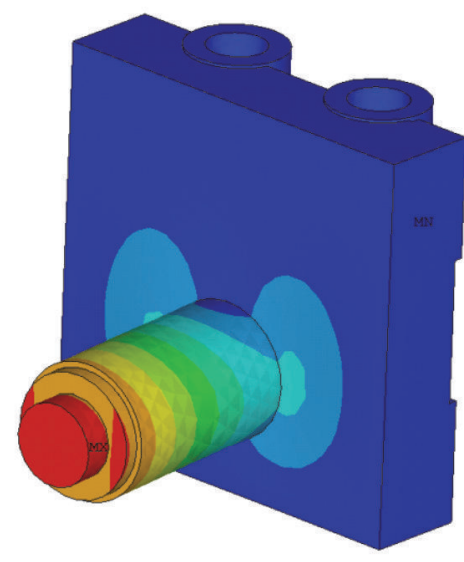

(b) The second order

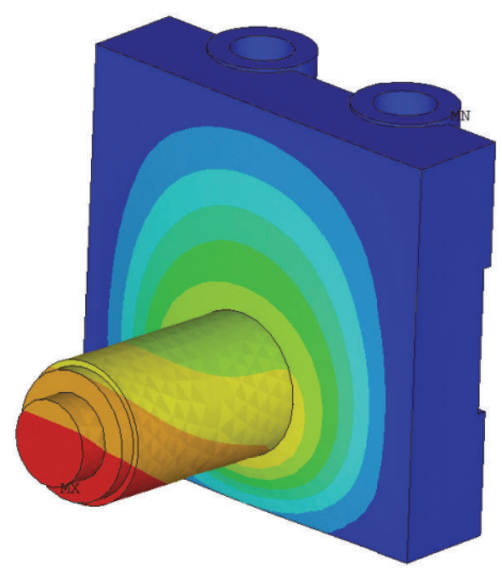

(c) The third order

Figure 8: Modal shapes of the first three-order frequencies.
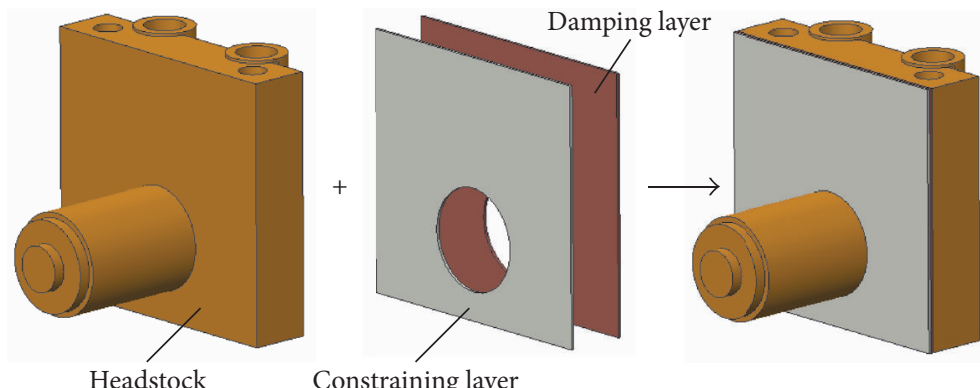

FIGURE 9: Hybrid headstock with damping material.

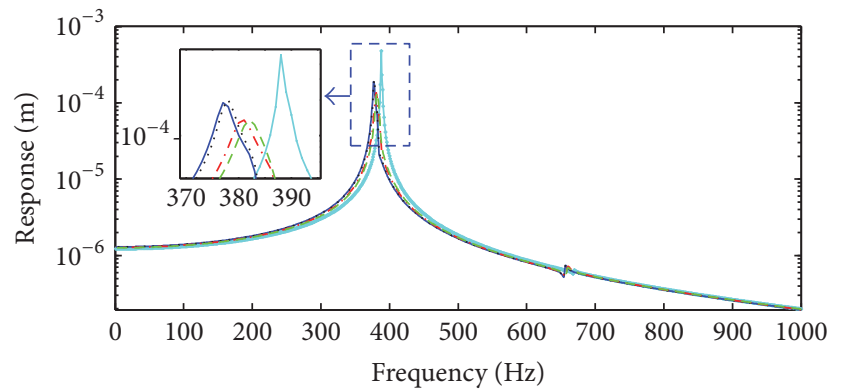

—- Original structure

_ Damping layer $3 \mathrm{~mm}$, constraining layer $3 \mathrm{~mm}$

.... Damping layer $5 \mathrm{~mm}$, constraining layer $3 \mathrm{~mm}$

...- Damping layer $5 \mathrm{~mm}$, constraining layer $5 \mathrm{~mm}$

- - - Damping layer $7 \mathrm{~mm}$, constraining layer $5 \mathrm{~mm}$

Figure 10: Response of structure with different thickness.

The modal analysis is performed, with the first threeorder natural frequencies being $380.66 \mathrm{~Hz}, 386.88 \mathrm{~Hz}$, and $658.62 \mathrm{~Hz}$, respectively. Compared to original structure, the natural frequencies almost unchanged. The first three-order modal loss factor is calculated by MSE method, with the values of $0.437 \%, 0.421 \%$, and $0.194 \%$. Harmonic response analysis with mode superposition method is performed, and the response curve is shown as in Figure 11. It can be seen that the response amplitude of hybrid headstock decreased obviously compared to the original structure. Thus, the treatment with damping material is effective and feasible to improve the damping capacity of the headstock.

\section{Experiment Verification of Headstock with Damping Material}

4.1. Experiment Set and Methods. A headstock specimen is prepared and the vibration responses are measured in order to verify the effectiveness of the damping material. The testing apparatus consists of an input module (B\&K 3050), an impulse hammer ( $B \& K$ 8206), and an accelerometer (B\&K 4506). Because the actual supports and fixations of the headstock in working situation are hardly realized, free support is selected here. The headstock is freely suspended by a rubber rope. The frequency response of the headstock is tested as shown in Figure 12.

First of all, the frequency response of the original headstock is tested. The hit location should keep away from the modal shape nodes and obvious response should be obtained. In the experiment several locations were hit to observe the responses, and finally the location where the most modes are excited and the responses are obvious was chosen. 


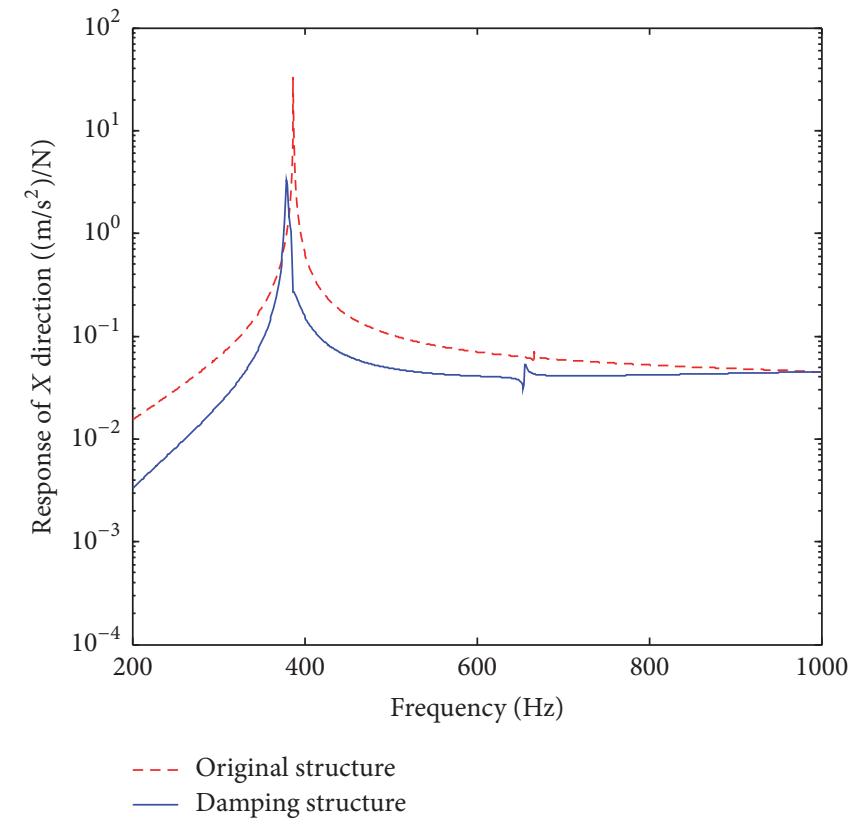

(a) Frequency response of $X$ direction

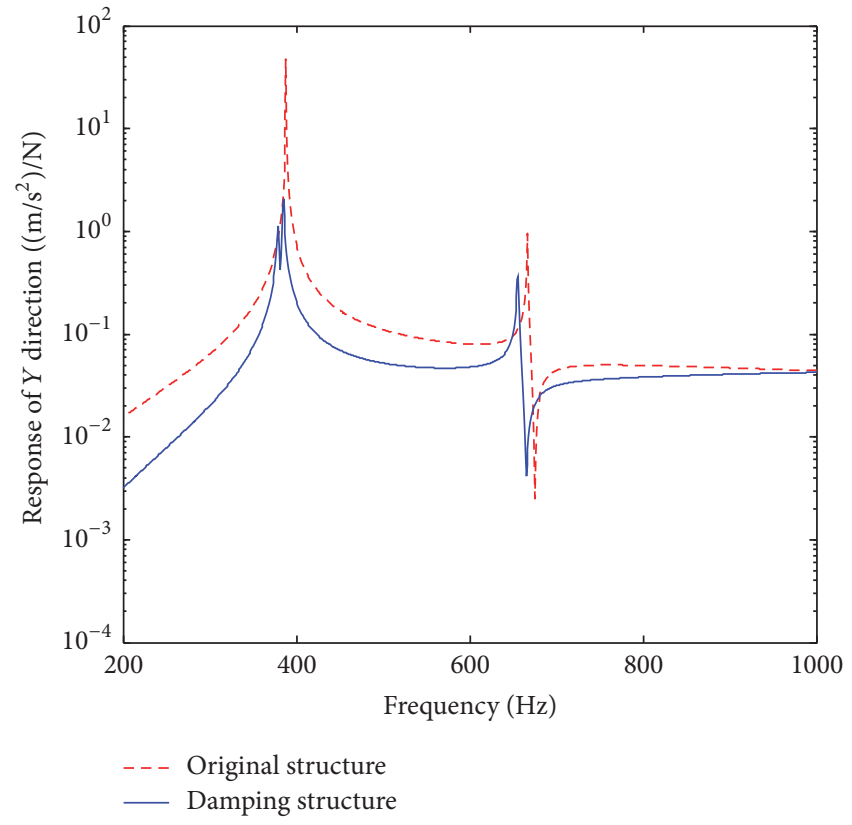

(b) Frequency response of $Y$ direction

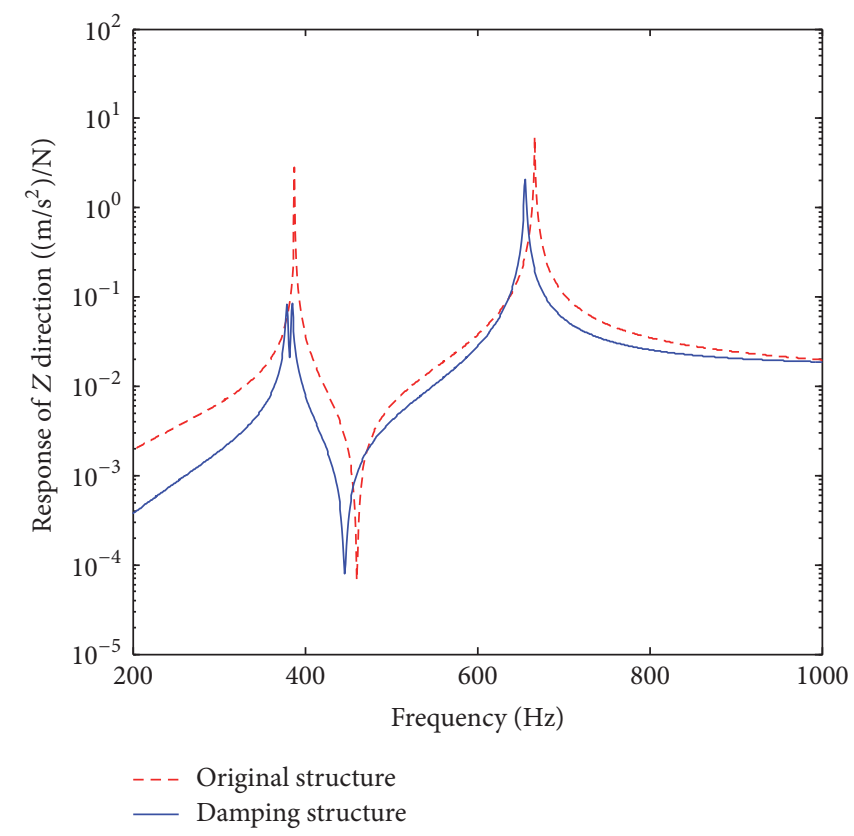

(c) Frequency response of $Z$ direction

FIGURE 11: Frequency response of headstock with damping material and original structure.

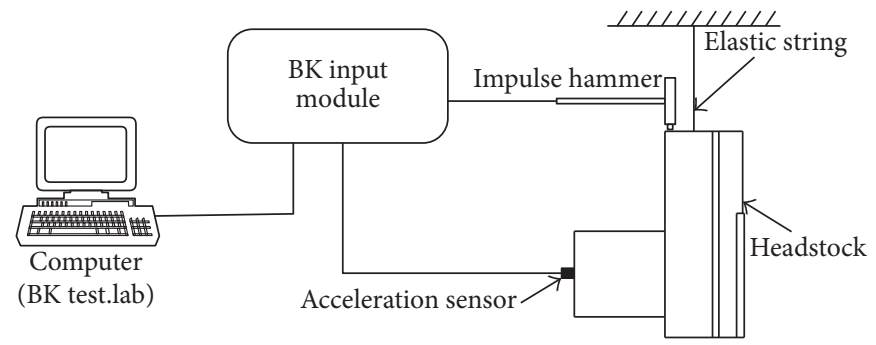

FIGURE 12: Measuring apparatus for the frequency response of the headstock. 


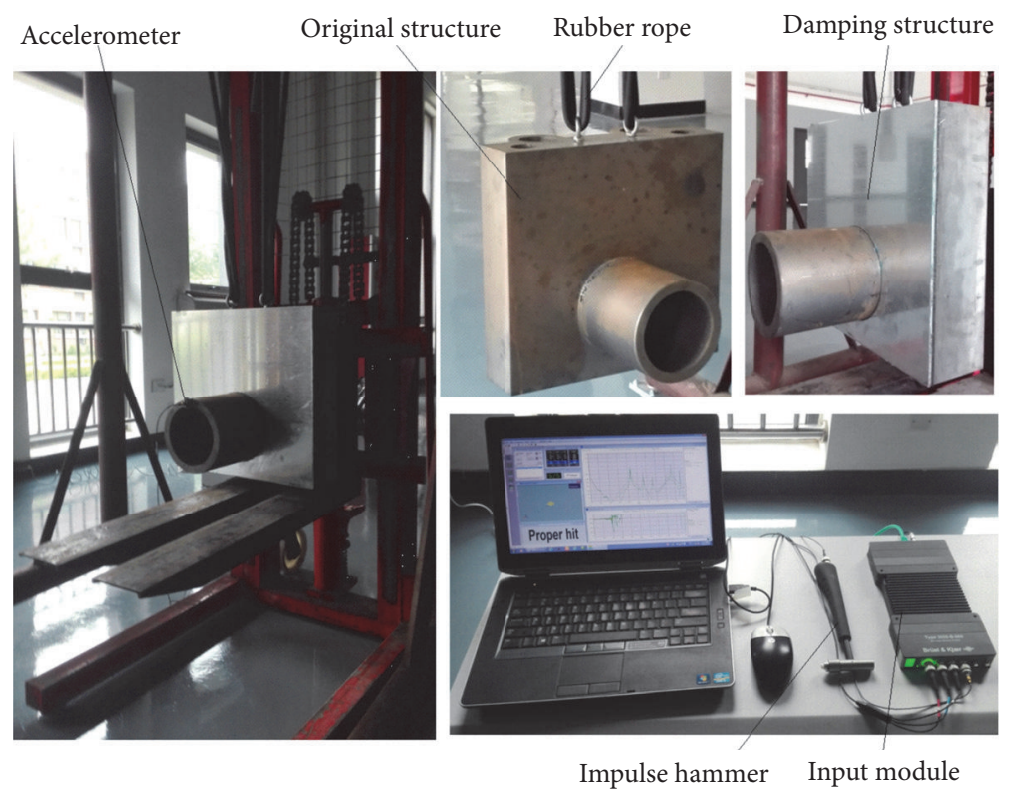

FIgURE 13: Experiment setup of the headstock.

Secondly, the damping layer and the constraining layer are adhesively bonded to the surface of the headstock by epoxy resin adhesive. Lastly, the frequency response of the hybrid headstock is tested as shown in Figure 13.

4.2. Discussion of Experiment Results. The frequency response curves in three directions between original and hybrid headstock are shown in Figure 14. In the $X$ and $Y$ direction, the response amplitude of the first-order natural frequency is largest. In the $Z$ direction, the largest amplitude occurs at the second-order natural frequency. The values of natural frequency and response amplitude by experiment of two structures are shown in Table 3. Compared with two structures, it can be seen that there is little variation of the natural frequency, but the damping material can significantly reduce the peak response at the natural frequency. The response amplitude of three directions decreases by $86 \%, 63 \%$, and $82 \%$, respectively. The results indicate that the effectiveness of the damping material is satisfactory.

\section{Topology Optimization of CLD Structure for the Headstock}

In the damping treatment applications to the headstock or other basic large components of the machine tool, full coverage CLD treatments are evidently not practical. First of all, some small components are needed to be assembled on the surface of these components. Secondly, according to the distribution of strain energy shown as in Figure 15, only some parts of viscoelastic material play a main role to the damping capacity. Thirdly, full coverage treatment adds excessive mass to the structure and influences the static and dynamic properties. In this section, topology optimization is implemented to achieve best performance with the constraint of material removal rate and natural frequency. For the response amplitude of first- and second-order frequencies is evidently greater than others, the maximum weighted modal loss factor is selected to be the objective, which is defined by $\eta=0.5 \eta_{1}+0.5 \eta_{2}$. When the material removal rate is limited to $50 \%$, the model for topology optimization can be shown as follows:

$$
\begin{array}{ll}
\text { Find } & e=\left[e_{1}, e_{2}, e_{3}, \ldots, e_{n}\right]^{T} \\
\text { Max } & \eta=0.5 \eta_{1}+0.5 \eta_{2} \\
\text { s.t. } & V=\sum_{i=1}^{N} e_{i} v_{i} \leq 0.5 V_{0} \quad e_{i}=\{0,1\} .
\end{array}
$$

A program is compiled to finish topology optimization using ANSYS parametric design language. The optimization result is shown in Figure 16, where the blue color stands for the removal elements and the red color stands for the reserved elements. It can be seen that the reserved parts agree well with distribution of strain energy.

The curve of removal rate varying with the iteration number is shown as in Figure 17. It can be seen that before the iteration number reaches 20 the removal rate increases quickly to reach $20 \%$, and the values tended to increase slowly to reach $50 \%$. The curve of first three orders of modal loss factor varying with the removal rate is shown in Figure 18 . When the removal rate is $50 \%$, the first three natural frequencies of optimized structure are $380.37 \mathrm{~Hz}, 386.61 \mathrm{~Hz}$, and $658.73 \mathrm{~Hz}$, respectively. And the first three modal loss factors are $0.355 \%, 0.322 \%$, and $0.191 \%$, respectively. The values of natural frequency and modal loss factor for two structures are listed in Table 4 . The simulation reveals that the applied volume decreases by $50 \%$ under the circumstance that the modal loss factor decreases by less than $23.5 \%$ compared to the original full coverage structure. The result shows that topology optimization can achieve a satisfactory optimal 


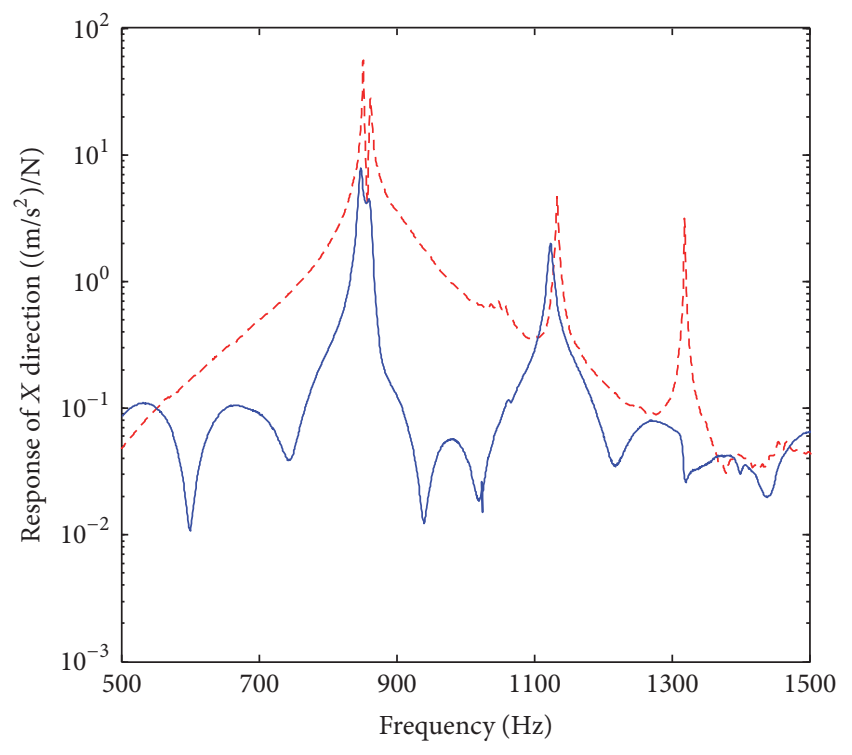

- - Original structure

—_ Damping structure

(a) $X$ direction of experiment

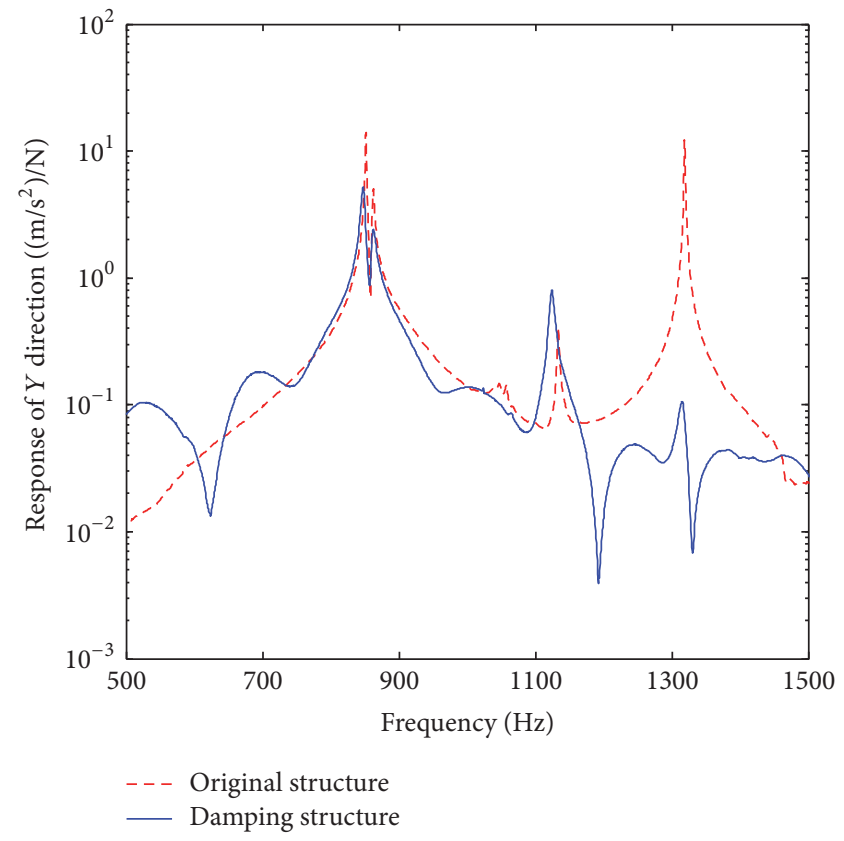

(b) $Y$ direction of experiment

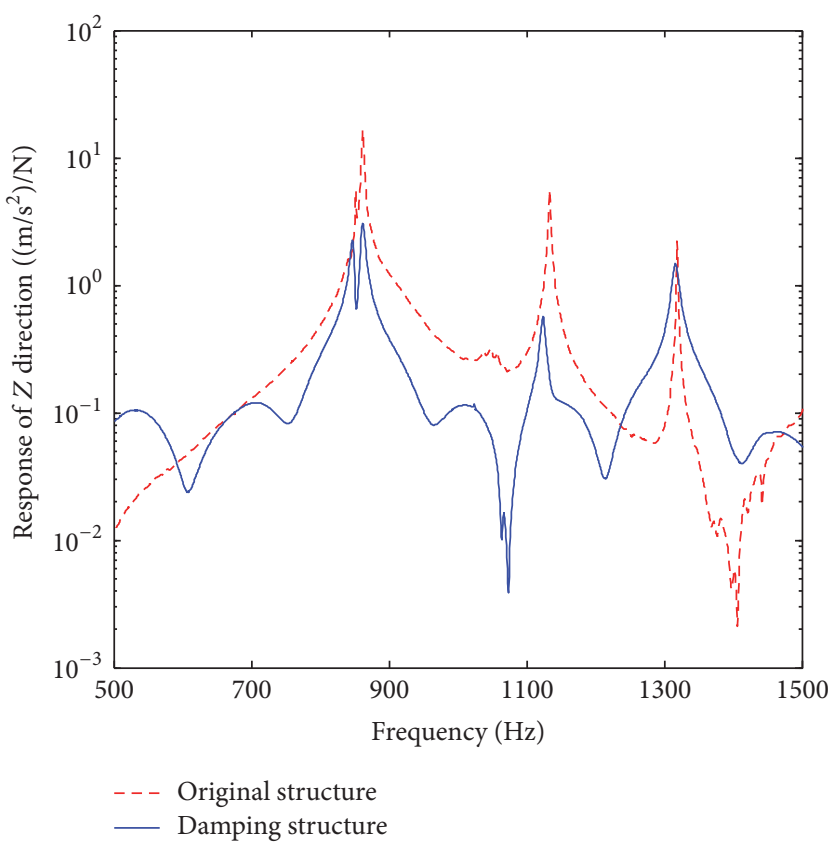

(c) $Z$ direction of experiment

FIGURE 14: Experiment frequency response curve of the headstock.

TABLE 3: Comparison of natural frequency and response amplitude for two structures.

\begin{tabular}{|c|c|c|c|c|c|c|}
\hline & \multicolumn{3}{|c|}{ Natural frequency $(\mathrm{Hz})$} & \multicolumn{3}{|c|}{ Response amplitude $\left(\left(\mathrm{m} / \mathrm{s}^{2}\right) / \mathrm{N}\right)$} \\
\hline & 1 st & 2nd & 3rd & $X$ direction & $Y$ direction & $Z$ direction \\
\hline Original structure & 852 & 863 & 1133 & 55 & 14.0 & 16.5 \\
\hline Hybrid structure & 846 & 861 & 1123 & 7.8 & 5.2 & 3.0 \\
\hline Change rate & $0.7 \%$ & $0.2 \%$ & $0.9 \%$ & $86 \%$ & $63 \%$ & $82 \%$ \\
\hline
\end{tabular}




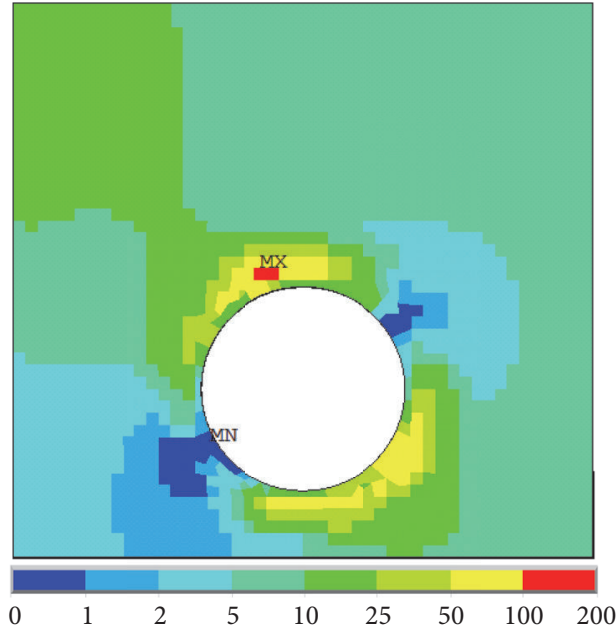

(a) The first order

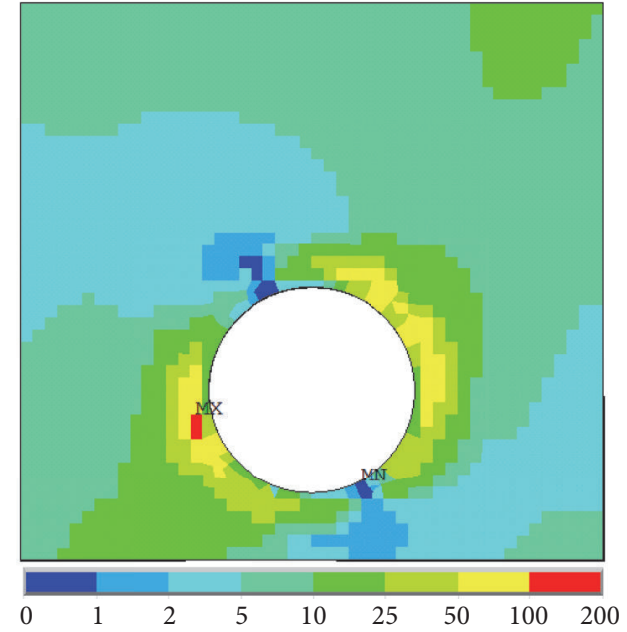

(b) The second order

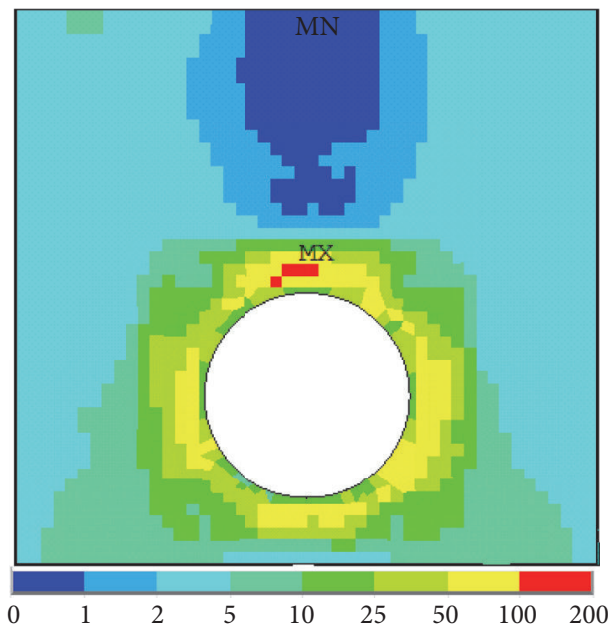

(c) The third order

FIGURE 15: Modal Strain Energy distribution of damping plate.

TABLE 4: Comparison of natural frequency and modal loss factor for two structures.

\begin{tabular}{lcccccc}
\hline & \multicolumn{3}{c}{ Natural frequency $(\mathrm{Hz})$} & \multicolumn{3}{c}{ Modal loss factor (\%) } \\
& 1st & 2nd & 3rd & 1st & 2nd & 3rd \\
\hline Full coverage & 380.66 & 386.88 & 658.62 & 0.437 & 0.421 & 0.194 \\
Topo results & 380.37 & 386.61 & 658.73 & 0.355 & 0.322 & 0.191 \\
Change rate & $0.01 \%$ & $0.01 \%$ & $0.01 \%$ & $18.8 \%$ & $23.5 \%$ & $1.5 \%$ \\
\hline
\end{tabular}

result. And this result can guide the design of the headstock. For instance, the threaded hole and the oil hole should be arranged at the area without the damping material.

\section{Conclusion}

To improve the damping capacity, a hybrid headstock is designed by adhesively bonding a damping layer and constraining layer to the surface of the cast headstock. For such complex damping structure, it can be expediently analyzed using MSE method. The dynamic characteristic of the hybrid headstock is investigated analytically and experimentally. It is found that the response amplitudes of hybrid headstock in three directions decrease by $86 \%, 63 \%$, and $82 \%$ than those of the original cast one.

To obtain the optimal configuration of damping material, topology optimization method is proposed. In this method the constraint is the material removal rate and natural frequency, and the objective is the maximum weighted modal 

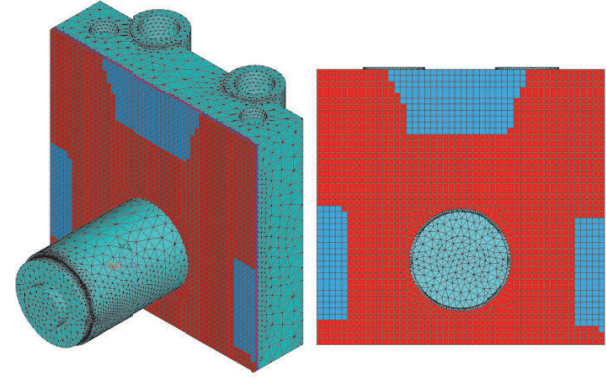

(a) Removal rate $20 \%$
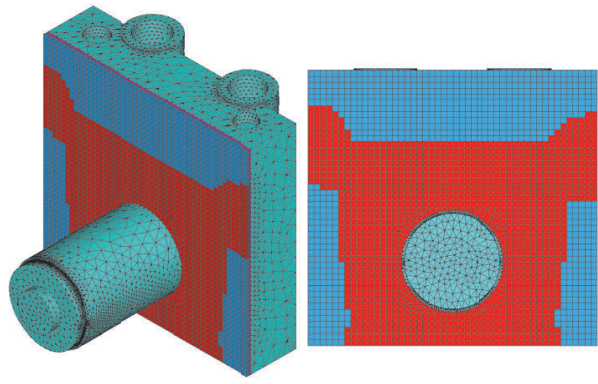

(c) Removal rate $40 \%$

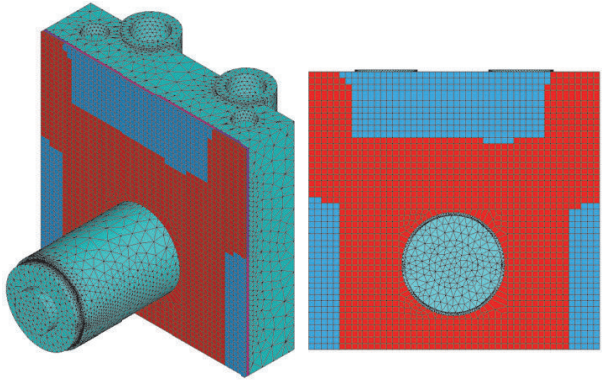

(b) Removal rate $30 \%$

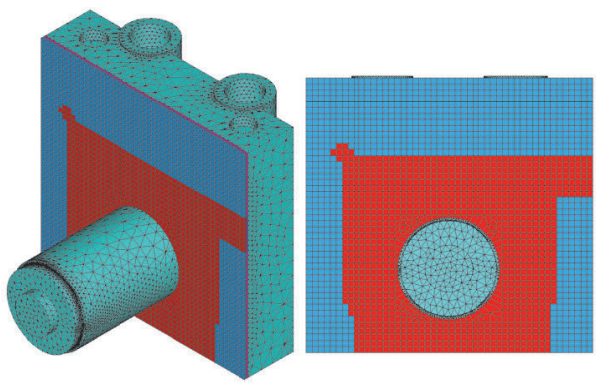

(d) Removal rate $50 \%$

FIGURE 16: Optimization result with material.

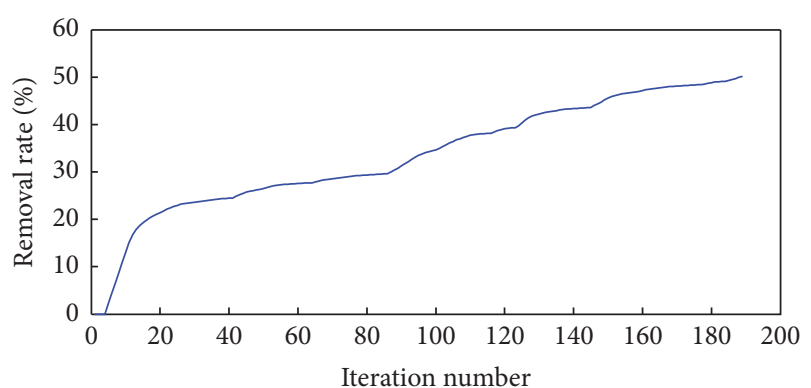

FIGURE 17: Iteration histories of removal rate.

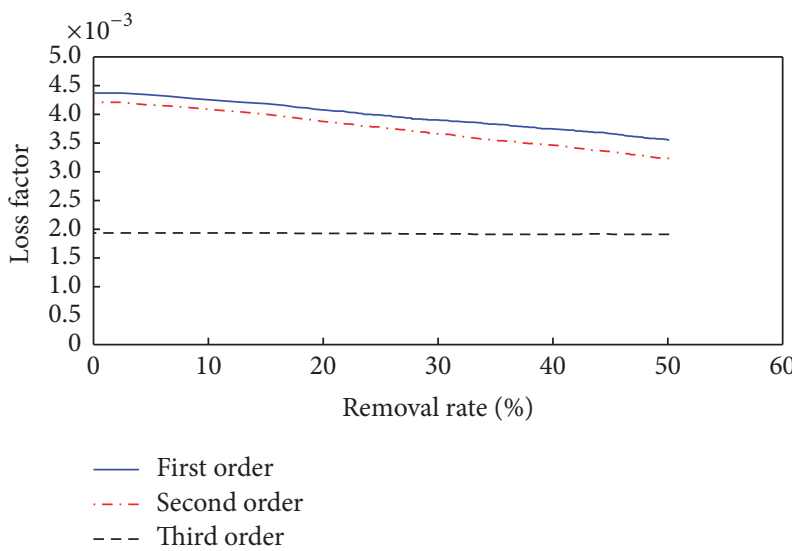

FIGURE 18: Change of the modal loss factor with the removal rate.

loss factor. The optimization results indicate that the added weight of damping material decreases by $50 \%$, and the first two orders of modal loss factor decrease by less than $23.5 \%$ compared to the original full cover structure.

\section{Competing Interests}

All the authors declare that there is no conflict of interests regarding the publication of this paper.

\section{Acknowledgments}

This research project is supported by the State S\&T Projects for Upmarket NC Machine and Fundamental Manufacturing Equipment of China (nos. 2013ZX04005-013, 2014ZX04014011, 2015ZX04005-001, and 2016ZX04004-002, resp.).

\section{References}

[1] J.-H. Kim and S.-H. Chang, "Design of $\mu$-CNC machining centre with carbon/epoxy composite-aluminium hybrid structures containing friction layers for high damping capacity," Composite Structures, vol. 92, no. 9, pp. 2128-2136, 2010.

[2] A. Rashid and C. M. Nicolescu, "Design and implementation of tuned viscoelastic dampers for vibration control in milling," International Journal of Machine Tools \& Manufacture, vol. 48, no. 9, pp. 1036-1053, 2008.

[3] S. H. Chang, P. J. Kim, D. G. Lee, and J. K. Choi, "Steel-composite hybrid headstock for high-precision grinding machines," Composite Structures, vol. 53, no. 1, pp. 1-8, 2001.

[4] D. G. Lee, S. H. Chang, and H. S. Kim, "Damping improvement of machine tool columns with polymer matrix fiber composite material," Composite Structures, vol. 43, no. 2, pp. 155-163, 1998. 
[5] F. P. Wardle, S. J. Lacey, and S. Y. Poon, "Dynamic and static characteristics of a wide speed range machine tool spindle," Precision Engineering, vol. 5, no. 4, pp. 175-183, 1983.

[6] E. M. Kerwin, "Damping of flexural waves by a constrained viscoelastic layer," Journal of the Acoustical Society of America, vol. 31, no. 7, pp. 952-962, 1959.

[7] R. Ross, E. E. Ungar, and E. M. Kerwin, "Damping of plate of flexural vibrations by means of viscoelastic laminate," in Proceedings of the Structural Damping-A Colloquium on Structural Damping Held at the ASME Annual Meeting, pp. 49-88, 1959.

[8] D. J. Mead and S. Markus, "The forced vibration of a three-layer, damped sandwich beam with arbitrary boundary conditions," Journal of Sound and Vibration, vol. 10, no. 2, pp. 163-175, 1969.

[9] C. D. Johnson and D. A. Kienholz, "Finite element prediction of damping in structures with constrained viscoelastic layers," AIAA journal, vol. 20, no. 9, pp. 1284-1290, 1982.

[10] A. K. Lall, N. T. Asnani, and B. C. Nakra, "Vibration and damping analysis of rectangular plate with partially covered constrained viscoelastic layer," Journal of vibration, acoustics, stress, and reliability in design, vol. 109, no. 3, pp. 241-247, 1987.

[11] A. K. Lall, N. T. Asnani, and B. C. Nakra, "Damping analysis of partially covered sandwich beams," Journal of Sound and Vibration, vol. 123, no. 2, pp. 247-259, 1988.

[12] J.-L. Marcelin, S. Shakhesi, and F. Pourroy, "Optimal constrained layer damping of beams: experimental and numerical studies," Shock \& Vibration, vol. 2, no. 6, pp. 445-450, 1995.

[13] M. Alvelid, "Optimal position and shape of applied damping material," Journal of Sound and Vibration, vol. 310, no. 4-5, pp. 947-965, 2008.

[14] G. Lepoittevin and G. Kress, "Optimization of segmented constrained layer damping with mathematical programming using strain energy analysis and modal data," Materials and Design, vol. 31, no. 1, pp. 14-24, 2010.

[15] Z. Z. Guo, Y. Z. Chen, K. W. Deng, and Q. Hou, "Study on topological optimization design of constrained damping plate based on evolutionary structural optimization," Journal of Machine Design, vol. 23, no. 10, pp. 3-5, 2006.

[16] Z. Fang and L. Zheng, "Topology optimization for minimizing the resonant response of plates with constrained layer damping treatment," Shock and Vibration, vol. 2015, Article ID 376854, 11 pages, 2015.

[17] S. Y. Kim, C. K. Mechefske, and I. Y. Kim, "Optimal damping layout in a shell structure using topology optimization," Journal of Sound and Vibration, vol. 332, no. 12, pp. 2873-2883, 2013. 


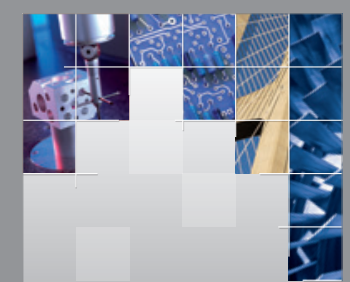

\section{Enfincering}
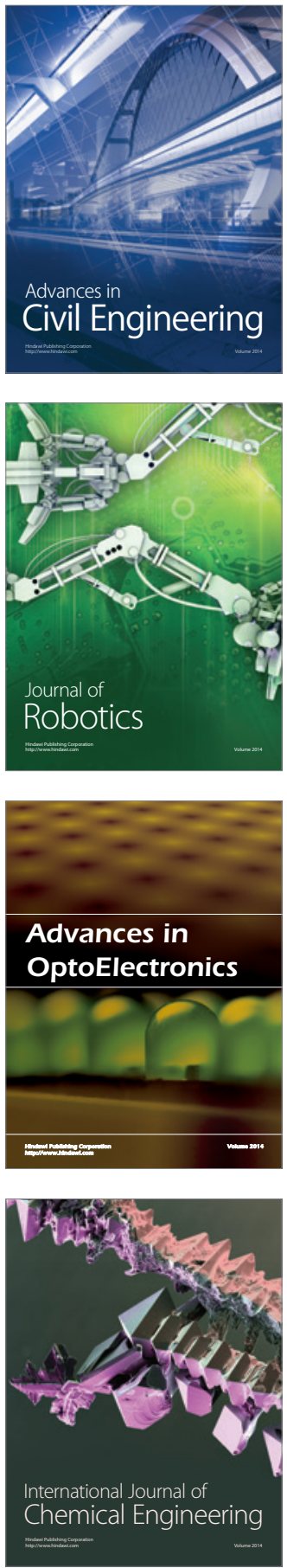

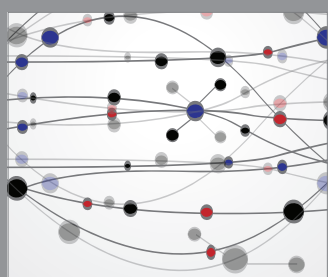

The Scientific World Journal

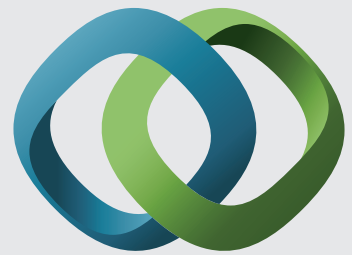

\section{Hindawi}

Submit your manuscripts at

https://www.hindawi.com
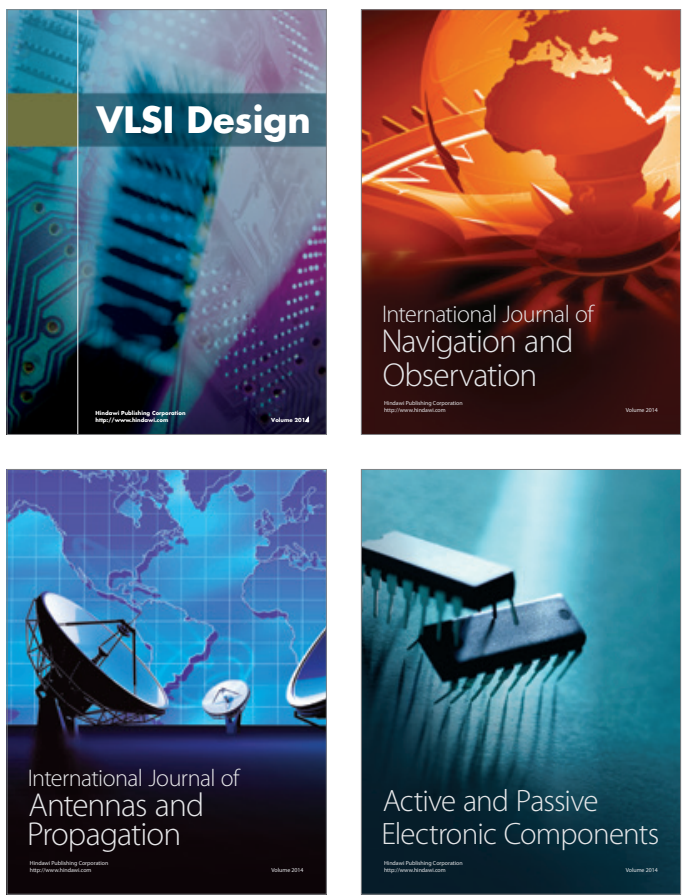
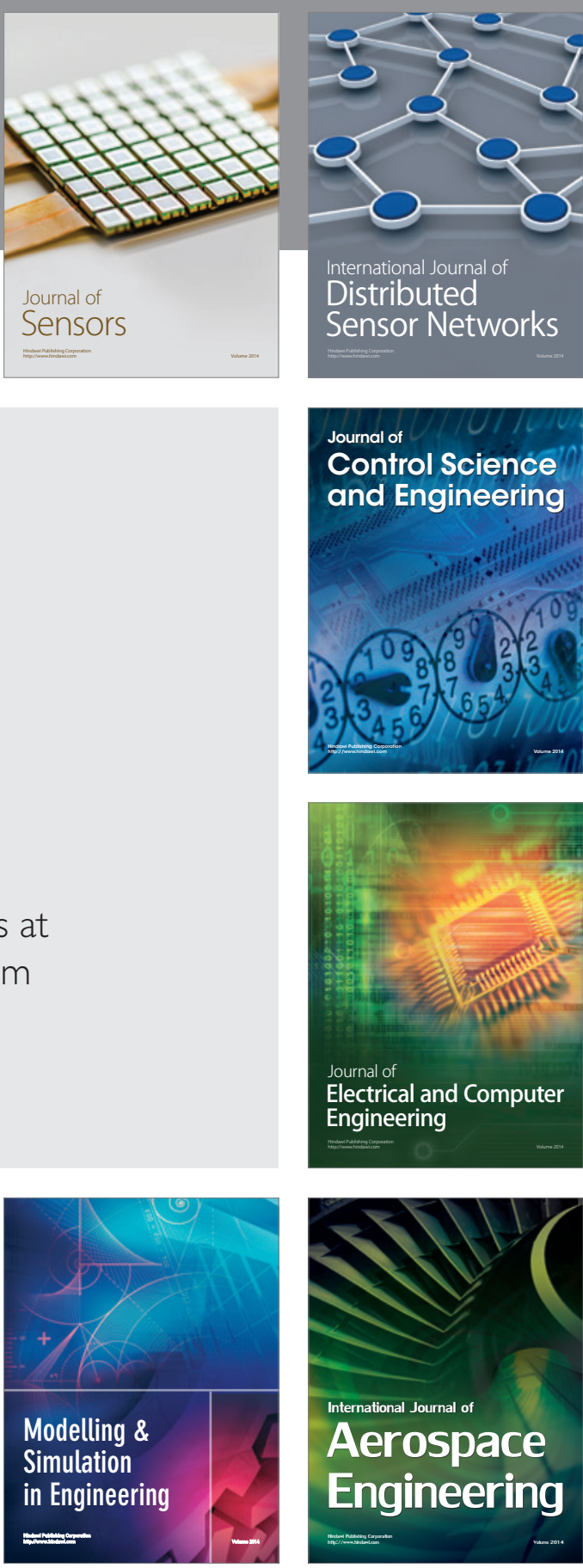

International Journal of

Distributed

Sensor Networks

$-$

Joumal of

Control Science

and Engineering
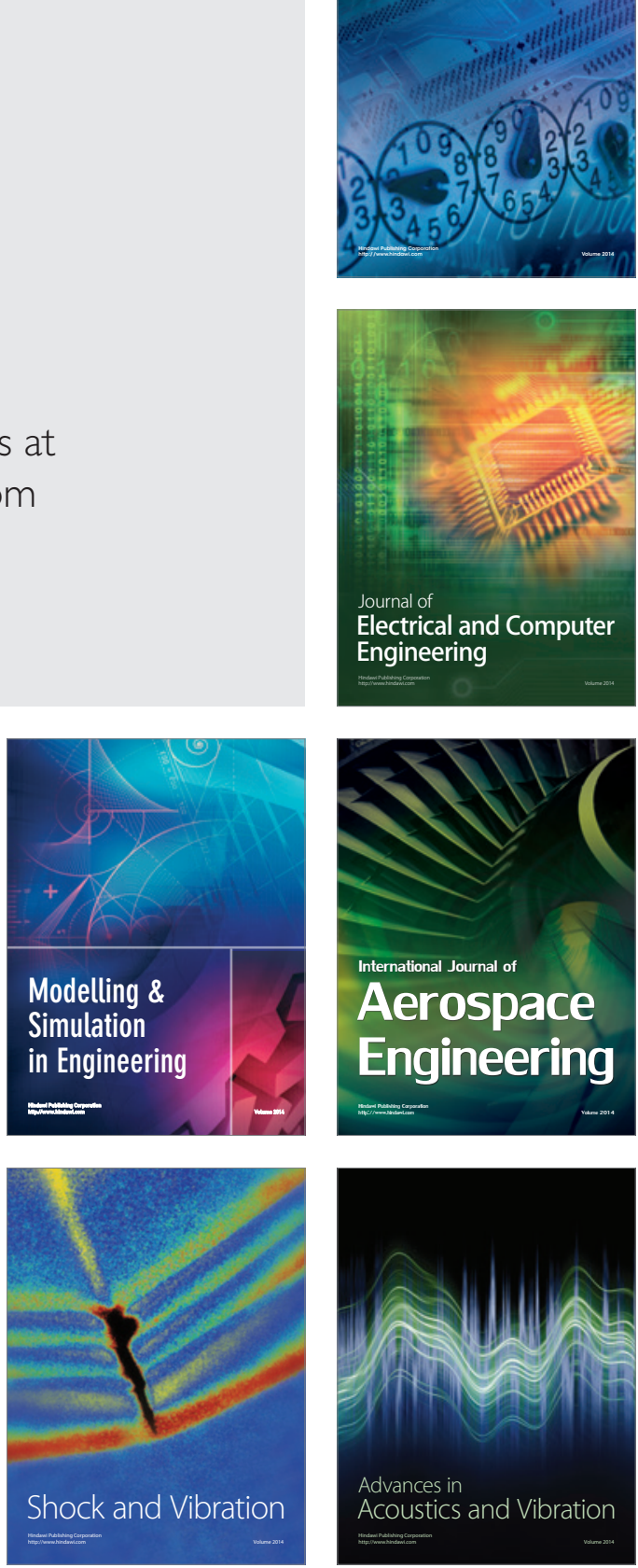